\title{
Reflexões sobre o componente ideopolítico do trabalho profissional do assistente social
}

\author{
Reflections on the ideopolitical component of the professional work of the social worker
}

\author{
Luciana Gonçalves Pereira de Paula*
}

\begin{abstract}
Resumo:
O presente artigo apresenta reflexões acerca do componente ideopolítico do Serviço Social considerando-o inerente ao trabalho profissional do/a assistente social. Destaca, sob a forma de eixos analíticos, algumas considerações que agrupam certos equívocos frequentes em meio a este debate, como: a confusão entre prática profissional e militância política; a consideração de uma prática profissional supostamente apolítica; a identificação do componente ideopolítico enquanto prática profissional crítica; e a percepção deste componente enquanto práxis revolucionária. Posteriormente, aponta algumas questões significativas para uma compreensão mais aprofundada em relação ao componente ideopolítico do Serviço Social: a origem desse componente; o Serviço Social como produto e produtor das relações sociais; os desafios apresentados pela realidade contemporânea à construção de uma intervenção profissional crítica; e as possibilidades para a sintonia com os interesses históricos da classe trabalhadora. Este mergulho reflexivo tem por objetivo subsidiar a construção de intervenções profissionais sustentadas em aportes teórico-metodológicos afinados com o projeto ético-político em hegemonia no Serviço Social, buscando ao atendimento dos reais interesses dos sujeitos com os quais o/a assistente social trabalha.
\end{abstract}

Palavras-Chave: Serviço Social. Dimensões do trabalho profissional. Projeto ético-político.

\begin{abstract}
:
This article presents reflections on the social-political component of Social Work - considering it inherent to the professional work of the social worker. It highlights, in the form of analytical axes, some considerations that group certain frequent misunderstandings amidst this debate, such as the confusion between professional practice and political militancy; the consideration of a supposedly nonpolitical professional practice; the identification of the political-ideological component as a critical professional practice; and the perception of the political-ideological component as a revolutionary praxis. Subsequently, it points out some significant issues for a deeper understanding of the socialpolitical component of Social Service: the origin of this component; Social Service as a product and producer of social relations; the challenges presented by contemporary reality to the construction of a critical professional intervention; and the possibilities for attunement to the historical interests of the working class. This reflective dive aims to subsidize the construction of professional interventions supported by theoretical and methodological contributions attuned to the ethical-political project in hegemony in Social Work, seeking to meet the real interests of the subjects with whom the social worker works.
\end{abstract}

Keywords: Social Work. Dimensions of professional work. Ethical-political project.

\footnotetext{
* Doutora em Serviço Social pela Universidade Federal do Rio de Janeiro. Docente da Faculdade de Serviço Social da Universidade Federal de Juiz de Fora.
} 


\section{Introdução}

O Serviço Social se constitui em uma profissão eminentemente interventiva, ou seja, é na prática que a profissão se encerra e informa sua finalidade. Por isso, a prática profissional é a condição essencial para que o Serviço Social seja reconhecido enquanto profissão e para que ocupe um lugar na divisão social e técnica do trabalho. Mas, este processo interventivo não pode ser compreendido em si mesmo e não se revela a si próprio. O processo de intervenção do/a assistente social possui um significado social que não se revela de imediato, não se mostra no ato em si do fazer profissional. "A prática profissional não tem o poder miraculoso de se revelar a si própria." (IAMAMOTO, 1991, p. 59).

Para que o/a assistente social possa realmente compreender o significado social da sua intervenção é preciso desvendar o movimento das classes sociais e das suas relações entre si, com a sociedade e com o Estado. É por meio do desvelamento das relações sociais que se pode desvendar o Serviço Social enquanto atividade socialmente necessária que possui efeitos na vida social, ao mesmo tempo em que sofre suas influências. Assim, a prática profissional é mediatizada pela correlação de forças entre as classes sociais, estabelecendo limites e possibilidades onde pode se mover o/a assistente social. Seu desenvolvimento se dá a partir da realidade social, tendo como eixo central a luta de classes - o conflito capital/trabalho.

O processo interventivo desenvolvido pelo/a assistente social possui um efeito que incide, diretamente, nas condições sociomateriais dos sujeitos com os quais trabalha. " [...] o Serviço Social interfere na reprodução da força de trabalho por meio dos serviços sociais previstos em programas, a partir dos quais se trabalha nas áreas de saúde, educação, condições habitacionais e outras" (IAMAMOTO, 2001, p. 67). Mas, esse/a profissional é, essencialmente, chamado/a para constituir-se em agente de "linha de frente" nas relações entre a população e a instituição (IAMAMOTO, 2000).

Neste sentido, a ação profissional possui uma atuação esclarecedora junto à população em relação aos seus direitos e aos mecanismos necessários para obtê-los. Estes serviços prestados pelo/a assistente social contribuem para que as necessidades básicas e urgentes de sobrevivência dos/as trabalhadores/as sejam atendidas, contribuindo para a sua reprodução. É dessa maneira que o/a assistente social atende, por meio das ações desenvolvidas em seu cotidiano profissional, tanto aos interesses dos/as trabalhadores/as quanto aos interesses da classe dominante. 
Os/as assistentes sociais, desde a gênese da profissão, foram historicamente requisitados pela classe dominante para exercer funções de persuasão e coerção sobre as formas de organização dos/as trabalhadores/as impulsionando-os/as a um processo de adesão frente às configurações do capital. Assim, por meio da prestação de serviços sociais, os/as profissionais realizam uma intervenção que incide diretamente na esfera ideopolítica da vida dos/as trabalhadores/as - seja para enfraquecer ou reforçar os seus reais interesses.

Percebemos, assim, que o/a assistente social possui, na sua intervenção profissional, um componente material-assistencial - que se configura através da prestação de serviços, concessão de benefícios, execução de programas e projetos, etc. Inerente a este componente material-assistencial existe outro componente que é ideopolítico, que influencia a forma de viver e de pensar dos sujeitos por ele/a atendidos. Este componente constitui o que há de subjetivo na intervenção profissional do/a assistente social. "O assistente social presta serviços e/ou administra serviços sociais que são a base material a partir de qual desenvolve uma ação ideológica, política e educativa" (CENTRO LATINO AMERICANO DE TRABAJO SOCIAL, 1985, p. 59).

Por exemplo, quando o assistente social viabiliza o acesso a um óculos, uma prótese, está fornecendo algo que é material e tem uma utilidade. Mas o assistente social não trabalha só com coisas materiais. Tem também efeitos na sociedade como um profissional que incide no campo do conhecimento, dos valores, dos comportamentos, da cultura, que por sua vez, têm efeitos reais interferindo na vida dos sujeitos. Os resultados de suas ações existem e são objetivos, embora nem sempre se corporifiquem como coisas materiais autônomas, ainda que tenham uma objetividade social (e não material) [...] (IAMAMOTO, 2001, p. 68).

Estes componentes da intervenção profissional são indissociáveis. O componente ideopolítico é inerente ao componente material-assistencial porque, ao desenvolver qualquer ação, o/a assistente social difunde, junto aos sujeitos com os quais trabalha valores, formas de pensar e concepções de mundo.

O componente ideopolítico que perpassa a prática profissional do/a assistente social articula convicções políticas e concepções ideológicas. Entretanto, esses elementos - o político e o ideológico - encontram-se absolutamente interligados no momento da intervenção profissional. A política e a ideologia possuem naturezas distintas e guardam uma relativa autonomia entre si, mas apresentam-se sempre de forma articulada.

Assim, ao definir o componente ideopolítico presente na intervenção profissional do/a assistente social, estamos considerando a política como um espaço de luta onde encontram-se em disputa projetos societários diferenciados. A ideologia, por sua vez, é uma concepção de mundo que se manifesta em todos os aspectos da vida coletiva. É mais do que 
um conjunto de ideias, pois está relacionada com a capacidade de inspirar atitudes concretas e proporcionar orientação para a ação. "É, portanto, na ideologia e pela ideologia que uma classe pode exercer hegemonia sobre outras, isto é, pode assegurar a adesão e o consentimento das grandes massas" (BOTTOMORE, 2001, p. 186).

Neste sentido, o objetivo do presente artigo consiste em pontuar algumas questões centrais que perpassaram esse debate, trazendo à tona algumas considerações, sob a forma de eixos analíticos, que agrupam alguns equívocos frequentes e algumas questões significativas em relação ao debate em torno do componente ideopolítico do Serviço Social.

O método utilizado para análise dos eixos analíticos é o materialista históricodialético, por ser esse capaz de desvelar as contradições inerentes à sociedade capitalista, e que perpassam o Serviço Social, em uma perspectiva de totalidade.

O principal recurso metodológico utilizado foi a pesquisa bibliográfica, debruçandose sobre obras publicadas na área do Serviço Social, a partir da década de 1960 - tomando como marco o Movimento de Reconceituação - e que debruçam-se sobre o debate do componente ideopolítico da profissão ${ }^{1}$.

\section{Alguns Equívocos Acerca do Componente Ideopolítico da Intervenção Profissional do/A Assistente Social}

\section{1ำ Equívoco: a prática profissional enquanto militância política}

Este equívoco possui suas raízes no Movimento de Reconceituação² e acompanhou o desenvolvimento do Serviço Social configurando, por muitas vezes, uma compreensão distorcida do componente ideopolítico da prática profissional do/a assistente social.

O encontro entre a profissão e o complexo universo marxista aconteceu em meio ao Movimento de Reconceituação, inicialmente através dos múltiplos marxismos, onde, na

\footnotetext{
${ }^{1}$ Dentre os autores pesquisados encontram-se: Diego Palma (1987), Vicente de Paula Faleiros $(1985,1991,1993)$, Marilda Villela lamamoto (2000, 2001, 2007), José Paulo Netto (1992, 1996, 1999, 2004), Marina Maciel Abreu (2002), Yolanda Guerra (2007) e Ana Maria de Vasconcelos (2002), ressaltando que a análise apresentada não recai sobre a totalidade das obras destes autores, mas sobre as elaborações que contribuem para uma melhor compreensão da dimensão iideopolítica do Serviço Social.

2 “O marco inicial da Reconceituação foi o 'I Seminário Regional Latino-Americano de Serviço Social’, realizado em maio de 1965 em Porto Alegre, com a presença de 415 participantes do Brasil, Uruguai e Argentina" (NETTO, 2005 , p. 9). O Movimento de Reconceituação constituiu uma indagação global sobre todos os componentes e todas as dimensões do Serviço Social. Ele não teve mais do que uma década de existência - de 1965 a 1975 -, mas seus reflexos provocaram erosões irreversíveis nas bases de cunho tradicional do Serviço Social.
} 
maioria das vezes, o personagem mais ausente era o próprio Marx. "Em outras palavras: foi a aproximação de um marxismo sem Marx" (IAMAMOTO, 2001, p. 211).

Assim, o primeiro encontro entre a categoria profissional e a tradição marxista não deu-se por meio das fontes clássicas, mas através de manuais e panfletos políticos partidários e sindicais - de divulgação do marxismo.

A leitura de divulgadores desta tradição intelectual à qual tivemos acesso, predominantemente a partir da militância política, forneceu-nos um determinado e problemático "recorte" que se encaixava às requisições postas naquele momento histórico para a profissão: o nosso primeiro encontro com o marxismo capturou deste os seus elementos ideopolíticos, como aportes para a afirmação da ruptura em níveis mais gerais, ressaltando o embate contra a neutralidade profissional (SANTOS, 2007, p. 1).

Deste modo, "o encontro do Serviço Social com a perspectiva crítico-dialética deu- se por meio do filtro da prática político-partidária" (IAMAMOTO, 2001, p. 210), configurandose em uma aproximação ideológica do marxismo. Esta aproximação realizou a convocação dos/as profissionais para que estes assumissem um compromisso político com a classe trabalhadora, redimensionando sua análise sobre a sociedade e sobre a sua própria função social, enquanto assistente social. Por meio deste caminho, muitas inquietações próprias da militância política e partidária foram automaticamente transferidas para o âmbito da prática profissional.

Sem deixar de ser importante naquele momento, esta radicalidade no posicionamento político provocada pela apropriação apenas ideológica do marxismo mistificou alguns aspectos da profissão devido à falta de clareza relativa a pontos essenciais do marxismo ausentes (ou praticamente ausentes) das formulações às quais tivemos acesso (SANTOS, 2007, p. 2).

A relação de identidade que estabeleceu-se entre prática a militante e a prática profissional foi responsável por dubiedades que acabaram por confundi-las, em muitos momentos, deixando de lado suas diferenças.

Por isso, equivocada é a concepção que dogmatiza os esquemas formais da política partidária como modelos que deveriam ser reproduzidos no Serviço Social. Uma perspectiva profissional pode se articular a uma perspectiva partidária e vice-versa, essencialmente quando ambas possuem uma mesma perspectiva de classe, mas são práticas que se desenvolvem em campos diferenciados e possuem significados distintos.

Deste modo, debater sobre o componente ideopolítico da intervenção profissional do assistente social não significa atribuir ao profissional um papel de militância política. "Sabe- 
se que a dimensão política da profissão não se confunde com o partido político - trata-se de uma categoria cravejada por diferenças sociais e ideológicas [...]" (IAMAMOTO, 2007, p. 229).

\section{2ำ Equívoco: a prática profissional supostamente apolítica}

Ao longo da década de 1980, ocorreu um segundo momento referente ao processo de aproximação do Serviço Social com a tradição marxista caracterizado, predominantemente, por uma apropriação epistemológica (SANTOS, 2007).

O marxismo estruturalista - ou simplesmente estruturalismo - de Althusser constituiu-se em uma das maiores influências em meio ao debate teórico desenvolvido no Serviço Social ${ }^{3}$. Tal influência muito contribuiu para a centralidade que a teoria assumiu - em detrimento da realidade - na profissão, ao longo nos anos de 1980. O teoricismo que resultou deste movimento produziu equívocos que se expressam na apreensão do marxismo como um modelo que se "aplica" na prática.

Tem-se aqui a percepção generalizada que emergiu da apropriação epistemológica do marxismo pelo Serviço Social: a de que deveria existir uma identidade entre teoria e prática; esta última seria moldada pela teoria de forma que o produto final correspondesse à teoria "aplicada" (SANTOS, 2007, p. 6).

Esta concepção foi responsável pela formulação da famosa afirmativa "na prática a teoria é outra". E, juntamente com parte dos/as profissionais que atribuíram ao componente ideopolítico da profissão uma conotação messiânica e heroica, de transformação da realidade, estimulou também o seu oposto. Nutriu grupos de profissionais com críticas à tradição marxista acusando-a de não oferecer aos/às assistentes sociais instrumentos e técnicas próprios que Ihes permitissem "aplicar" a teoria à realidade.

Ainda hoje, sustentados por estas críticas, muitos/as assistentes sociais afirmam não gostar de política e acreditam que seja possível debater o Serviço Social sem realizar discussões políticas. Deste modo, podemos perceber que a concepção do componente

\footnotetext{
${ }^{3}$ De acordo com Coutinho (2006, p. 72), Althusser tentou realizar, através de suas obras, a impossível conciliação entre marxismo e estruturalismo, "na medida em que os conceitos centrais do marxismo eram negados pelo estruturalismo [...]. Assim, no essencial, não seria equivocado afirmar que Althusser representa - no marxismo contemporâneo - uma posição conservadora ou de direita. Recusando o historicismo, o papel criador da práxis, o humanismo como concepção de mundo, o althusserianismo contribui - consciente ou inconscientemente para reforçar uma concepção burocrática e conservadora do socialismo. Na versão de Althusser, o marxismo tende a converter-se numa técnica de dominação (econômica, política etc.), com inteiro abandono dos seus aspectos humanistas (democratização, construção do homem novo etc.). Com isso, converte-se numa tendência restauradora, que pretende - sob o véu de um 'modernismo' científico - recolocar em circulação determinados conteúdos próprios do estalinismo, de uma concepção tecnicista e manipulatória do socialismo (COUTINHO, 2010, p. 185).
} 
ideopolítico da intervenção profissional encontra-se diretamente ligada a uma determinada concepção de mundo (TEIXEIRA, 1991). A imagem de um Serviço Social apolítico vincula-se a várias teorias conservadoras que separam os conceitos: teoria e prática, filosofia e ciência, ciência e técnica, perdendo a perspectiva da totalidade. Neste sentido, o componente ideopolítico da profissão aparece como um formalismo doutrinal, moralista, pois desliga a questão social do fazer humano concreto, produtivo e cultural, na medida em que identifica a miséria humana como distinta da relação entre capital e trabalho.

Este é outro equívoco: a negação da existência de uma esfera ideopolítica permeada de contradições sociais geradas pela luta de classes que atravessa cotidianamente a prática profissional.

3o Equívoco: o componente ideopolítico enquanto prática profissional crítica

Outro equívoco que pode ser cometido ao se pensar sobre o componente ideopolítico da intervenção do/a assistente social, é a imediata correlação deste com uma prática profissional crítica, vinculada aos interesses políticos e ideológicos construídos historicamente pela classe trabalhadora.

O fato de o Serviço Social possuir um componente ideopolítico, que lhe é inerente, não pressupõe que este esteja naturalmente vinculado a um projeto societário de ruptura com a ordem do capital. Ao contrário, como vimos anteriormente, a prática profissional de a maior parte da categoria profissional manteve-se atrelada ao projeto societário da classe dominante por um longo período. E, mesmo depois da conquista hegemônica de um projeto profissional articulado aos interesses do conjunto dos trabalhadores, práticas profissionais conservadoras - sejam tradicionais, tecnocráticas, neoconservadoras ou aparentemente radicais, como nos aponta Netto (1996) - não desapareceram.

Portanto, o componente ideopolítico contido nos processos interventivos dos/as assistentes sociais pode concretizar-se, através das ações por estes/as desenvolvidas, em perspectivas críticas e/ou conservadoras de atuação.

Assumir uma perspectiva crítica de intervenção profissional significa compreender o seu componente ideopolítico e empreender esforços para que as ações planejadas e executadas venham a se somar com a luta dos trabalhadores contra os processos de exploração e dominação capitalistas, e não substituí-la. Em nossa atual conjuntura, representa desenvolver ações profissionais que somem esforços com todos os movimentos que se contraponham aos ajustes neoliberais e à barbárie capitalista. 
Faz-se então necessário ao profissional que, pela via de conhecimento teórico, da escolha consciente por valores universais, da direção política que atribui a sua prática, bem como de uma postura renovada e qualificada, transcenda a mera cotidianidade para alcançar o patamar do exercício crítico, competente e comprometido (GUERRA, 2007, p. 12).

\section{4o Equívoco: o componente ideopolítico enquanto práxis revolucionária}

Um último equívoco a ser apontado refere-se aos limites do componente ideopolítico da intervenção profissional do/a assistente social. Diz respeito à atribuição de práticas revolucionárias aos/às assistentes sociais, colocando-lhes sobre os ombros uma responsabilidade que não compete a uma categoria profissional e sim a uma classe social.

Os/as assistentes sociais não são "líderes messiânicos" encarregados de conduzir o processo de transformação da sociedade e nem assim devem se comportar. Entre os objetivos profissionais apontados pelo nosso projeto ético-político não encontra-se a condução da classe trabalhadora no processo de transformação social. Análises neste sentido não levam em consideração que os principais atores políticos de nossa sociedade são as classes sociais e não as profissões.

As reais transformações revolucionárias na sociedade só podem ser impulsionadas pela iniciativa e pelos esforços da classe trabalhadora. Não cabe ao/à assistente social, enquanto profissional, o papel revolucionário de transformar a sociedade capitalista. A tarefa revolucionária de subverter a ordem do capital em detrimento da conformação de uma nova sociabilidade é do conjunto dos/as trabalhadores/as.

Desta forma, o Serviço Social, enquanto profissão situada na esfera da defesa dos direitos, não realiza a superação da ordem capitalista. Todas as ações desenvolvidas pelos/as assistentes sociais, mesmo que defendam interesses reais do conjunto dos trabalhadores, cabem muito bem dentro dos limites do sistema capitalista.

O que este/a profissional pode - e deve - construir são intervenções que potencializem, que contribuam, que reforcem a luta por uma outra sociedade sendo que esta, na sua essência, precisa ser conduzido pelos trabalhadores. "Nestas circunstâncias, a atividade dos profissionais se pode definir como progressista quando apoia, reforça ou estimula o esforço transformador daqueles que são os atores básicos da mudança social" (PALMA, 1987, p. 27).

No entanto, para que os/as profissionais possam desenvolver ações que fortaleçam o processo de transformação social, faz-se necessário que ele esteja em construção. Esta é 
uma tarefa que não cabe ao Serviço Social, porque é muito maior que qualquer profissão. Não é competência do/a assistente social, enquanto profissional, instituir esse processo, mas uma de suas atribuições pode ser a sua contribuição no desenvolvimento desta ação coletiva.

\section{Algumas Questões Relevantes para o Debate do Componente Ideopolítico do Serviço Social}

1ㅁ Questão: a origem do componente ideopolítico do Serviço Social.

Superando as imprecisões que circundam o debate acerca do componente ideopolítico da intervenção profissional do/a assistente social, levando muitos profissionais a uma compreensão equivocada sobre tal componente, podemos concluir que sua origem encontra-se na contradição essencial da sociedade capitalista - a contradição entre capital e trabalho. Esta contradição permeia não apenas o Serviço Social, mas qualquer atividade profissional - e não profissional -, fazendo com que seu processo interventivo seja perpassado por interesses antagônicos.

Sendo o Serviço Social uma atividade socialmente determinada e historicamente legitimada, o/a assistente social, por meio de sua atuação profissional, atende tanto aos interesses institucionais - geralmente atrelados aos interesses dominantes -, quanto aos interesses dos sujeitos por ele atendidos - majoritariamente membros da classe trabalhadora. $E$, somente através da compreensão desta dinâmica, ou seja, apenas por meio de uma correta apreensão do componente ideopolítico inerente à sua prática profissional, pode empreender esforços na elaboração de estratégias que venham a reforçar os interesses históricos dos trabalhadores - uma vez que no decorrer do seu processo interventivo, repassa para os sujeitos que compõem o seu público-alvo valores, princípios e concepções de mundo.

Isto significa que o exercício profissional participa de um mesmo movimento que permite a continuidade da sociedade de classes e cria as possibilidades de sua transformação. Como a sociedade nas quais se inscreve o exercício profissional é atravessada por projetos sociais distintos - projeto de classes para a sociedade -, cria o terreno sócio-histórico para a construção de projetos profissionais também diversos, indissociáveis dos projetos mais amplos para a sociedade. Tem-se, portanto, a presença de forças sociais e políticas reais - não mera ilusão -, que permitem à categoria profissional estabelecer estratégias político-profissionais no sentido de reforçar interesses das classes subalternas, alvo prioritário das ações profissionais. Sendo a profissão atravessada por relações de poder, dispõe de um caráter essencialmente político, o que não decorre apenas das intenções pessoais do assistente social, mas dos condicionantes histórico-sociais dos contextos em que se insere e atua (IAMAMOTO, 2008, p. 8). 
Portanto, o Serviço Social encontra-se inserido no processo de reprodução das relações sociais gestadas na sociedade capitalista. Esta reprodução das relações sociais é a "reprodução da totalidade do processo social, a reprodução de determinado modo de vida que envolve o cotidiano da vida em sociedade: o modo de viver e de trabalhar, de forma socialmente determinada, dos indivíduos em sociedade" (IAMAMOTO; CARVALHO, 2003, p. 72).

O componente ideopolítico da intervenção profissional do/a assistente social é inerente ao Serviço Social pelo fato dele estar instituído em meio às relações sociais cujos contornos são estabelecidos pela sociedade capitalista, num processo incessante de disputas políticas e ideológicas entre classes sociais antagônicas. Estas disputas ideopolíticas - que configuram-se na luta de classes - expressam seus interesses e suas propostas através de projetos societários vinculados a uma das duas classes fundamentais da sociedade capitalista: capitalistas e trabalhadores.

Esta é a origem, a raiz do componente ideopolítico do Serviço Social. Assim sendo, tal componente não deriva da vontade ou da intenção, nem tão pouco da atuação ou do compromisso do/a assistente social com os interesses dos trabalhadores ou com as demandas do capital. Ele configura-se na medida em que a intervenção profissional é polarizada pelas estratégias desenvolvidas pelas diferentes classes sociais. E, somente através da compreensão deste componente, o/a profissional pode ser capaz de elaborar suas próprias estratégias de atuação para que essas venham a fortalecer os interesses do capital ou do trabalho.

Deste modo, todas as profissões possuem um componente ideopolítico, este componente não é privilégio do Serviço Social. Ele é inerente a qualquer atividade coletiva e esta, por sua vez, encontra-se, inevitavelmente, vinculada a um dos projetos societários em disputa. Apenas a sua plena compreensão pode fazer com que a categoria profissional seja capaz de elaborar estratégias que venham a fortalecer um desses projetos societários.

Portanto, a correta apreensão em torno do componente ideopolítico do Serviço Social depende da compreensão teórica sobre a relação que se estabelece entre capital e trabalho, na sociedade capitalista, e sobre as contradições que se estabelecem a partir das classes fundamentais. Classes que não representam um conceito, um dado ou um pressuposto, mas que são um produto histórico real do movimento de produção e reprodução das relações sociais antagônicas estabelecidas pela ordem do capital. 
Portanto, a atuação do Serviço Social é visceralmente polarizada por interesses sociais de classes contraditórias, inscritos na própria organização da sociedade e que se recriam na nossa prática profissional, os quais não podemos eliminar. Só nos resta estabelecer estratégias profissionais e políticas que fortaleçam alguns dos atores presentes nesse cenário (IAMAMOTO, 1991, p. 60).

\section{Questão: o Serviço Social como produto e produtor das relações sociais}

O/a profissional do Serviço Social atua em meio a uma totalidade concreta que se encontra em constante movimento, em um processo de estruturação e reestruturação permanente. Por isso, o Serviço Social - assim como qualquer outra profissão - precisa ser considerado a partir de dois ângulos indissociáveis. O primeiro refere-se à profissão como uma realidade que é vivida por seus agentes e através destes torna-se representada em discursos teórico-ideológicos que são construídos sobre o exercício profissional. O segundo ângulo deste mesmo fenômeno que é a atividade profissional, diz respeito ao fato da atuação do/a assistente social ser uma atividade socialmente determinada por circunstâncias sociais objetivas.

Em relação ao primeiro ângulo, pode-se afirmar que o Serviço Social parece possuir certo privilégio em relação a outras atividades profissionais. A profissão assumiu o seu componente ideopolítico com a audácia necessária para propor um percurso profissional que venha a reforçar as tarefas da construção de uma nova ordem para além do capital.

No entanto, o segundo ângulo indica que a conjuntura produzida em determinados momentos históricos interfere diretamente na constituição da direção social da profissão e, consequentemente, no próprio processo interventivo realizado por seus agentes. O contexto histórico condiciona e, por vezes, ultrapassa a vontade e a consciência dos/as profissionais em relação às ações por eles desenvolvidas.

Portanto, a unidade entre estes dois ângulos é tão real quanto contraditória. Ela pode ocasionar uma defasagem entre as intencionalidades do profissional - expressas ou não em seu discurso - e o seu próprio fazer profissional. Nem sempre as representações que legitimam uma profissão caminham juntas com as condições propícias para o seu exercício e com os efeitos sociais que provoca.

Deste modo, fica evidente que existem muitos fatores que corroboram para que este descompasso aconteça. Fatores que vão além do domínio destes profissionais porque "a profissão não se constrói apenas internamente, pela 'exclusiva vontade dos seus membros' [...], o que nos mostra o justo limite para a autonomia profissional que o contexto históricosocial lhe coloca" (MONTAÑO, 2007, p. 197). 
3므 Questão: os desafios apresentados pela realidade contemporânea

O tempo presente acirra a naturalização das desigualdades sociais e a submissão das necessidades humanas ao poder do capital e do seu fetiche, características da sociedade capitalista (IAMAMOTO, 2007). E é dentro deste contexto, sob o efeito destas forças que se congregam para nos conduzir pelo caminho da indiferença diante do destino de enormes contingentes de trabalhadores, que atuam os/as assistentes sociais.

Desta forma, mesmo defendendo um projeto profissional que possui como horizonte a transformação radical deste modelo societário, o/a assistente social move-se em uma conjuntura onde o projeto societário hegemônico garante a efetividade dos interesses da classe dominante. E esta conjuntura faz com que as influências da crítica pós-moderna ao ideário da modernidade ecoem mais facilmente entre os profissionais do Serviço Social.

Atualmente, as críticas pós-modernas se contrapõem à perspectiva da totalidade, à existência de classes sociais antagônicas e ao ideário revolucionário. Segundo a perspectiva pós-moderna, a diversidade e a diferença dissolveram todas as antigas universalidades em uma pluralidade de estilos de vida e de identidades pessoais. E, se não existem mais interesses comuns e coletivos, não se faz mais necessária uma luta unificada por uma ideologia revolucionária. Não se faz mais necessária uma ruptura com o sistema de produção vigente na sociedade.

A dificuldade em se apreender a totalidade social, devido ao florescimento do pensamento pós-moderno, soma-se ao atual modelo de Estado regido pelos princípios neoliberais. Este modelo tem contribuído para um aprofundamento do processo de subordinação do Serviço Social. "Efetivamente, nele se prega (e pratica) a drástica diminuição e a minimização do Estado, dos recursos destinados às políticas sociais" (MONTAÑO, 2007, p. 107).

Este contexto ocasiona impactos diretos no Serviço Social, seja pela redução direta do número de assistentes sociais contratados pelo Estado, seja pelo processo de precarização das condições de trabalho, através da terceirização dos mesmos, como também pela diminuição drástica de financiamento e recursos necessários aos profissionais na execução das políticas sociais.

Isto aumenta a subordinação do assistente social, agora com menos recursos à sua disposição - e com menor demanda organizacional -, por ser um dos executores dessas políticas sociais, algumas das quais já são, para esses Estados, prescindíveis e descartáveis (MONTAÑO, 2007, p. 108). 
O processo de subordinação do/a assistente social é cotidianamente reforçado pelas demandas e cobranças institucionais que se impõem ao/à profissional em seus espaços sócioocupacionais. Os objetivos burocráticos da instituição tendem a comprimir e limitar a liberdade do/a assistente social, rotinizando as funções que realiza durante sua intervenção profissional.

$\mathrm{Na}$ posição de um/a empregado/a assalariado/a do capital que possui uma intervenção profissional voltada para os/as trabalhadores/as, o/a assistente social, muitas vezes, encontra-se em uma posição desconfortável, debatendo-se entre os interesses institucionais e as reais necessidades dos sujeitos junto aos quais trabalha.

4ạ Questão: o assistente social sintonizado com os interesses históricos da classe trabalhadora.

Os/as assistentes sociais, muitas vezes, encontram-se inseridos no contexto das políticas sociais setorizadas, parcializadas e focalizadas que segmentam a questão social em vários "problemas sociais".

\begin{abstract}
Com isso percebemos, primeiramente, que o tipo de demanda encaminhada ao assistente social, por parte do contratante-que fragmenta e autonomiza a realidade social, que transforma a "questão social' em "problemáticas" isoladas, as contradições estruturais em "disfunções" individuais, as consequências em causas, a "demanda social" em "demanda por serviços institucional-profissionais", os processos mediatizados pelas lutas de classe em questões imediatas e emergenciais -, usualmente não exige conhecimento teórico-crítico das teorias sociais e atualização acadêmica, numa perspectiva de totalidade, que permita o domínio dos fundamentos da "questão social". Exige, sim, conhecimento apurado de técnicas e informações dos recursos organizacionais, tanto quanto da população atendida, com a qual estabeleça uma boa relação de empatia, e sólidos conhecimentos setoriais. Pede-se ao assistente social atividades de triagem, encaminhamento, relatórios, comunicação e divulgação de ações, coordenação de grupos etc., ou seja, respostas imediatas a demandas emergenciais (MONTAÑO, 2007, p. 106).
\end{abstract}

Assim, o fato de o/a assistente social, na maioria das vezes, encontrar-se alocado no campo das políticas sociais, acaba propiciando à adesão deste/a profissional - mesmo que involuntária - a uma forma de pensar pautada na fragmentação da realidade social. Esta visão segmentada reflete-se na própria compreensão do profissional sobre os sujeitos com os quais trabalha.

A população receptora dos serviços é, muitas vezes, vista pelo/a profissional sob uma perspectiva fragmentada - como pobres, crianças, famílias, idosos, população de rua, entre outros - de acordo com as carências apresentadas.

“Assim, há a ausência de perspectiva de classe social dos profissionais, classificando a população receptora de seus serviços a partir do atendimento e da política social oferecida, 
não reconhecendo esta como pertencente a uma classe social - a classe trabalhadora." (CASSAB et al., 2006, p. 12).

Seguindo a mesma lógica, muitos são os/as assistentes sociais que identificam as demandas mais frequentemente apresentadas pelos sujeitos por ele atendidos como sendo de ordem individual, relacionadas à satisfação de necessidades pessoais e não coletivas.

\begin{abstract}
O assistente social tem dificuldade de enxergar esta demanda como uma demanda coletiva, isto é, de compreender o indivíduo inserido em uma classe. De entender o indivíduo alvo de sua intervenção como "corpo laborante", ou seja, o indivíduo que é pertencente a uma classe social e que, sobretudo, vivencia as contradições da relação entre capital e trabalho (CASSAB et al., 2006, p. 14).
\end{abstract}

Tais questões demonstram que muitos/as assistentes sociais não consegue visualizar os sujeitos com os quais trabalha como pertencentes a uma classe social. Não conseguem perceber que suas demandas individuais refletem a história de luta e resistência da classe trabalhadora.

Torna-se evidente a existência de um descompasso entre a concepção teórica dos sujeitos sociais, que se constituem como público alvo do Serviço Social, trabalhada no decorrer do processo de formação profissional e a apreensão de tais sujeitos por parte dos/as profissionais que encontram-se inseridos no mercado de trabalho.

Este descompasso, em muitos casos, é consequência do tensionamento que se sobrepõe aos/às assistentes sociais - contratados/as para materializar o vínculo entre as políticas sociais e seus destinatários - dentro de condições particulares de assalariamento que "põem esses profissionais em situação política, econômica e funcionalmente subordinada" (MONTAÑO, 2007, p. 104).

[...] sendo em geral seu salário (muitas vezes seu único meio de sustento) extremamente limitado; colocando-se numa tensa relação entre o patrão, ligado aos interesses das classes hegemônicas, ao capital, e o "usuário", ligado às classes subalternas, ao trabalhador; administrando ou implementando geralmente recursos escassos [...] (MONTAÑO, 2007, p. 104).

No entanto, todo o processo de subordinação do/a assistente social, para o qual contribuem fatores históricos, estruturais e conjunturais, pode ser enfrentado e, até mesmo, alterado, "pois a subordinação do assistente social é um fenômeno histórico e não natural. Portanto, assim como é construída, também pode ser destruída" (MONTAÑO, 2007, p. 108).

Não é nada fácil percorrer caminhos e consolidar intervenções críticas e sintonizadas com os interesses históricos da classe trabalhadora. No entanto, a prática profissional do/a 
assistente social não é apenas resultante de um processo histórico, ela é, também, produto teórico-prático dos/as agentes que a ela se dedicam. "A profissão é tanto um dado histórico, indissociável das particularidades assumidas pela formação e desenvolvimento de nossas sociedades, quanto resultante dos sujeitos sociais que constroem sua trajetória e redirecionam seus rumos" (IAMAMOTO, 2008, p. 9).

Este fator abre aos/às profissionais a possibilidade de lutar por uma atuação diferenciada que ultrapasse as barreiras impostas pelo contexto amplamente desfavorável. "Para isto, não basta ao Serviço Social restringir-se ao campo das políticas sociais que minimizam o desemprego e a miséria, mas buscar compreender criticamente as condições de trabalho que caracterizam a sociedade contemporânea" (MUSTAFA, 2004, p. 180).

Neste sentido, o atual - necessário e viável ${ }^{4}$ - projeto ético-político profissional hegemônico no Serviço Social configura-se como um importante norteador para as ações desenvolvidas pelos/as assistentes sociais. O valor central defendido por este projeto é a liberdade - "a liberdade concebida historicamente, como possibilidade de escolha entre alternativas concretas; daí um compromisso com a autonomia, a emancipação e a plena expansão dos indivíduos sociais" (NETTO, 1999, p. 15). Deste modo, percebemos que este projeto profissional vincula-se, claramente, a um projeto societário que traz como núcleo central a proposta da construção de uma sociedade sem relações de exploração e dominação de classe, etnia ou gênero.

A dimensão política do projeto é claramente enunciada: ele se posiciona a favor da equidade e da justiça social, na perspectiva da universalização do acesso a bens e a serviços relativos às políticas e programas sociais; a ampliação e a consolidação da cidadania são explicitamente postas como garantia dos direitos civis, políticos e sociais das classes trabalhadoras. Correspondentemente, o projeto se declara radicalmente democrático - considerada a democratização como socialização da participação política e socialização da riqueza socialmente produzida (NETTO, 1999, p. 16).

\footnotetext{
${ }^{4}$ [...] a viabilidade e atualidades histórica do projeto profissional encontra-se no fato de que ele fundamenta-se nos valores civilizatórios construídos nas lutas históricas da classe trabalhadora e em identidades coletivas (e aqui cabe uma menção especial aos interesses e necessidades dos sujeitos para os quais nossos serviços se destinam); rejeita os valores da sociedade burguesa, ao mesmo tempo que faz crítica interna dos desvalores (preconceitos) reproduzidos por essa sociabilidade; permite enfrentar o capitalismo e sua perspectiva de barbarização da vida (incluindo a precarização das condições e relações de trabalho, com destaque para as das assistentes sociais) e de potencializar as forças de enfrentamento e ruptura em relação ao ordenamento social capitalista; resiste aos novos e velhos irracionalismos, contribui para a construção de estratégias de resistência e de confronto à lógica do capital e expressa a necessidade da sua superação (ou da superação da pré-história da humanidade); representa as necessidades de um ser social que é íntegro, que busca a realização histórica da sua essência humana e da vida plena de sentidos (FORTI; GUERRA, 2014, p. 66).
} 
Segundo Vasconcelos (2002), sem um projeto sistematizado de intervenção profissional, a maioria dos/as assistentes sociais acaba empreendendo esforços no sentido de repassar aos sujeitos com os quais trabalha a sua análise sobre a realidade, os seus valores, as suas opiniões. Demonstram-se incapazes de produzir condições objetivas que criem possibilidades para que a própria população usuária realize um processo de reflexão sobre o seu cotidiano, a sua realidade e exercite seu potencial organizativo buscando romper com práticas controladoras e ampliar seus direitos. "Desse modo, repassar para os usuários a posição política dos profissionais, como um fim em si mesmo, acaba por exercer controle, através de um discurso pautado na solidariedade." (VASCONCELOS, 2002, p. 119).

O real enfrentamento dessa situação exige uma atuação profissional que extrapole a simples reprodução da normatização institucional e proponha a abertura de novas frentes de trabalho capazes de alargar as funções do/a assistente social diante da realidade social que a ele/a se apresenta, descortinando possibilidades até então não percebidas. Este processo implica em uma problematização teórica e histórica do contexto conjuntural e socioinstitucional do espaço onde se concretiza a intervenção profissional para decifrar o significado social de sua atuação, e assim, desvendar estratégias políticas, alianças e táticas possíveis de serem concretizadas no espaço profissional.

\section{Considerações Finais}

Os/as assistentes sociais podem desenvolver intervenções profissionais que provoquem mudanças na forma de pensar, de sentir, de viver e de lutar dos sujeitos com os quais trabalha. Estas intervenções podem estimular e potencializar a resistência dos/as trabalhadores/as fazendo com que, ainda na ordem vigente, surjam elementos de contestação, de rebeldia e de organização voltados para a constituição de uma nova sociabilidade.

Entretanto, para que o/a assistente social, através de sua intervenção, possa contribuir com a luta dos/as trabalhadores/as é preciso que esta luta esteja em construção. Estamos vivendo tempos de duro combate à luta organizada e, diante desta situação, muitos movimentos, organizações e mobilizações vêm sucumbindo - embora existam ainda, em todo o mundo, movimentos sociais e políticos combativos e resistentes aos ataques do capital.

Todavia, se o contexto não favorece o florescimento de experiências concretamente organizadas, o conjunto de trabalhadores/as que configura o público alvo do/a assistente 
social the oferece diariamente conteúdos de resistência à ordem vigente com os quais o/a profissional pode trabalhar e desenvolver inúmeras ações. Segundo lamamoto (2008, p. 04), nossa "sociedade apresenta um terreno minado de resistências e lutas travadas no dia a dia de uma conjuntura adversa para os trabalhadores, as quais carecem de maior organicidade para terem força na cena pública".

Muitas vezes, mesmo que não seja de forma consciente e com objetivos claramente definidos, os sujeitos com os quais o/a assistente social trabalha lhe apresentam manifestações de questionamento e oposição ao seu modo de vida e elas passam despercebidas pelos/as profissionais. Detectar focos de resistência dos/as trabalhadores/as e colocar-se a serviço destes/as no seu processo de mobilização deve constituir-se em atribuição privilegiada dos/as assistentes sociais.

\section{Referências}

ABREU, M. M. Serviço Social e a organização da cultura: perfis pedagógicos da prática profissional. São Paulo: Cortez, 2002.

BOTTOMORE, T. (Ed.). Dicionário do pensamento marxista. Rio de Janeiro: J. Zahar, 2001.

CASSAB, M. A. T. et al. O trabalho dos assistentes sociais na esfera pública: natureza, atribuições e particularidades: municípios da Zona da Mata Mineira. Juiz de Fora, MG, 2006. Mimeografado.

CENTRO LATINOAMERICANO DE TRABAJO SOCIAL - CELATS. Serviço social crítico: problemas e perspectivas. São Paulo: Cortez, 1985.

COUTINHO, C. N. Intervenções: o marxismo na batalha das ideias. São Paulo: Cortez, 2006.

COUTINHO, C. N. O estruturalismo e a miséria da razão. 2. ed. São Paulo: Expressão Popular, 2010.

FALEIROS, V. P. Metodologia e ideologia do trabalho social. 8. ed. São Paulo: Cortez, 1993.

FALEIROS, V. P. Relações sociais e sujeitos históricos da ação profissional. In: CONGRESSO BRASILEIRO DE ASSISTENTES SOCIAIS: Congresso Chico Mendes Serviço Social: as Respostas da Categoria aos Desafios Conjunturais, 4., 1991, São Paulo. Anais... São Paulo: Cortez, 1991.

FALEIROS, V. P. Saber profissional e poder institucional. São Paulo: Cortez, 1985.

FALEIROS, V. P. Sobre a possibilidade histórica do projeto ético-político profissional: a apreciação crítica que se faz necessária. In: FORTI, V; GUERRA, Y. Projeto ético-político do Serviço Social: contribuições à sua crítica. Rio de Janeiro: Lúmen Júris, 2014. p. 39-70.

FORTI, V; GUERRA, Y. Projeto ético-político do Serviço Social: contribuições à sua crítica. Rio de Janeiro: Lúmen Júris, 2014. 
GUERRA, Y. O projeto profissional crítico: estratégia de enfrentamento das condições contemporâneas da prática profissional. Serviço Social e Sociedade, São Paulo, v. 28, n. 91, p. 5-33, 2007.

IAMAMOTO, M. V. As dimensões ético-políticas e teórico-metodológicas no serviço social contemporâneo: trajetória e desafios. Disponível em:

<www.fnepas.org.br/pdf/servico_social_saude/texto2-2.pdf>. Acesso em: 30 maio 2008.

IAMAMOTO, M. V. O serviço social na contemporaneidade: trabalho e formação profissional. 5. ed. São Paulo: Cortez, 2001.

IAMAMOTO, M. V. Renovação e conservadorismo no Serviço Social: ensaios críticos. 5. ed. São Paulo: Cortez, 2000.

IAMAMOTO, M. V. Serviço Social em tempo de capital fetiche: capital financeiro, trabalho e questão social. São Paulo: Cortez, 2007.

IAMAMOTO, M. V. Serviço Social na contradição capital/trabalho: concepção da dimensão política na prática profissional. In: Serviço Social: as respostas da categoria aos desafios conjunturais. In: CONGRESSO BRASILEIRO DE ASSISTENTES SOCIAIS: Congresso Chico Mendes, 4., 1991, São Paulo. Anais... São Paulo: Cortez, 1991.

IAMAMOTO, M. V.; CARVALHO, R. Relações sociais e serviço social no Brasil: esboço de uma interpretação histórico-metodológica. 15. ed. São Paulo: Cortez, 2003.

MONTAÑO, C. A natureza do serviço social. São Paulo: Cortez, 2007.

MUSTAFA, A. Reflexões sobre o projeto ético-político do Serviço Social. Praia Vermelha: Estudos de Política e Teoria Social, Rio de Janeiro, n. 11, p. 168-183, 2004.

NETTO, J. P. A conjuntura brasileira: o Serviço Social posto à prova. Serviço Social e Sociedade, São Paulo, v. 15, n. 79, p. 5-26, 2004.

NETTO, J. P. A construção do projeto ético-político do Serviço Social frente à crise contemporânea. In: CAPACITAÇÃO em serviço social e política social. Brasília: CFESS, 1999. Módulo 1: crise contemporânea, questão social e Serviço Social. p. 91-109.

NETTO, J. P. Capitalismo monopolista e Serviço Social. São Paulo: Cortez, 1992.

NETTO, J. P. Ditadura e serviço social: uma análise do serviço social no Brasil pós-64. 6. ed. São Paulo: Cortez, 2002.

NETTO, J. P. O movimento de reconceituação: 40 anos depois. Serviço Social e Sociedade, São Paulo, v. 26, n. 84, p. 5-20, 2005.

NETTO, J. P. Transformações societárias e Serviço Social: notas para uma análise prospectiva da profissão no Brasil. Serviço Social e Sociedade, São Paulo, ano 17, n. 50, p. 87-132, 1996.

PALMA, D. A prática política dos profissionais: o caso do serviço social. São Paulo: Cortez, 1987. 
SANTOS, J. S. Apropriações da tradição marxista no Serviço Social. Cadernos Especiais, [Brasília], n. 42, p. 7, jan. /fev. 2007. Disponível em: <http://www.assistentesocial.com.br>. Acesso em:

TEIXEIRA, J. B. Concepção da dimensão política da prática profissional. In: CONGRESSO BRASILEIRO DE ASSISTENTES SOCIAIS: Congresso Chico Mendes, 4., 1991, São Paulo. Anais... São Paulo: Cortez, 1991.

VASCONCELOS, A. M. A prática do Serviço Social: cotidiano, formação e alternativas na área da saúde. São Paulo: Cortez, 2002. 
Recebido em:20/02/2018

Aceito em: 20/06/2018 